\title{
The long-term impact of diabetes on graft patency after coronary artery bypass grafting surgery: A substudy of the multicenter Radial Artery Patency Study
}

\author{
Saswata Deb, MD, ${ }^{\mathrm{a}, \mathrm{b}}$ Steve K. Singh, MD,${ }^{\mathrm{c}}$ Fuad Moussa, MD, ${ }^{\mathrm{a}}$ Hideki Tsubota, MD, ${ }^{\mathrm{a}}$ Dai Une, MD, ${ }^{\mathrm{d}}$ \\ Alex Kiss, PhD, ${ }^{\text {b,e }}$ George Tomlinson, PhD, ${ }^{\text {b,f,g }}$ Mehdi Afshar, BSc, ${ }^{a}$ Ryan Sless, BSc, ${ }^{a}$ \\ Eric A. Cohen, MD, ${ }^{\mathrm{a}}$ Sam Radhakrishnan, MD, ${ }^{\mathrm{a}}$ James Dubbin, MD, ${ }^{\mathrm{a}}$ Leonard Schwartz, MD, ${ }^{\mathrm{f}}$ and \\ Stephen E. Fremes, MD, a,b on behalf of the Radial Artery Patency Study Investigators
}

\begin{abstract}
Objectives: The study objective was to determine the impact of diabetes on radial artery and saphenous vein graft occlusion and clinical outcomes more than 5 years after coronary artery bypass surgery in the multicenter Radial Artery Patency Study (NCT00187356).

Methods: A total of 529 patients aged less than 80 years with triple-vessel disease undergoing coronary bypass surgery participated in this study. Angiographic follow-up occurred more than 5 years after surgery with annual clinical follow-up. The primary objective was to compare the proportion of complete graft occlusion between radial artery and saphenous vein grafts among diabetic and nondiabetic persons. Additional objectives included determining predictors of complete graft occlusion and comparison of major adverse cardiac events defined by cardiac death, late myocardial infarction, and reintervention.
\end{abstract}

Results: There were 148 of 529 patients (27.8\%) with diabetes; 269 patients (83/269 [30.9\%] diabetic) underwent late angiography at mean of $7.7 \pm 1.5$ years after surgery. In diabetic patients, the proportion of complete graft occlusion was significantly lower in the radial grafts $(4 / 83[4.8 \%])$ than in the saphenous grafts $(21 / 83$ $[25.3 \%])(P=.0004)$, and this was similar in nondiabetic patients $(P=.19)$. Multivariate modeling showed that the use of the radial artery and high-grade target vessel stenosis were protective against late graft occlusion, whereas female gender, smoking history, and elevated creatinine were associated with an increased risk; interaction between diabetic status and conduit type also was significant $(P=.02)$. Major adverse cardiac events were higher in diabetic patients $(23 / 148[15.5 \%]$ vs $35 / 381[9.2 \%], P=.04)$.

Conclusions: The use of the radial artery should be strongly considered in diabetic patients undergoing coronary bypass surgery, especially with high-grade target vessel stenosis. (J Thorac Cardiovasc Surg 2014;148:1246-53)

From the Schulich Heart Centre, ${ }^{\text {a }}$ Sunnybrook Health Sciences Centre, University of Toronto, Toronto, Ontario, Canada; Institute of Health Policy Management and Evaluation, ${ }^{\text {b }}$ University of Toronto, Toronto, Ontario, Canada; Texas Heart Institute, ${ }^{\mathrm{c}}$ Houston, Tex; University of Ottawa Heart Institute, ${ }^{\mathrm{d}}$ Ottawa, Ontario, Canada; Sunnybrook Research Institute, ${ }^{\mathrm{e}}$ Toronto, Ontario, Canada; Department of Medicine, ${ }^{\mathrm{f}}$ University Health Network, Toronto, Ontario, Canada; and Dalla Lana School of Public Health, ${ }^{\mathrm{g}}$ University of Toronto, Toronto, Ontario, Canada. The Radial Artery Patency Study was supported by a grant (MT-13883) from the Canadian Institutes of Health Research. Dr Deb is supported by the Vanier Canada Graduate Scholarship, Canadian Institutes of Health Research. Dr Fremes is supported by the Bernard S. Goldman Chair in Cardiovascular Surgery.

Disclosures: Eric A Cohen reports consulting fees from Astra Zeneca, Medtronic Vascular, and Abbott Vascular, and lecture fees from Abbott Vascular and Astra Zeneca. All other authors have nothing to disclose with regard to commercial support.

Read at the 94th Annual Meeting of The American Association for Thoracic Surgery, Toronto, Ontario, Canada, April 26-30, 2014.

The members of the Radial Artery Patency Study Group are as follows: Executive Committee: S.E. Fremes, E.A. Cohen, R. Feder-Elituv, A. Laupacis; Manuscript Committee: S.E. Fremes, E.A. Cohen, S. Deb, A. Laupacis, S.K. Singh; Steering Committee: S.E. Fremes, E.A. Cohen, A. Laupacis, C. Buller, N.D. Desai, L. Errett, R. Feder-Elituv, J.F. Morin, S. Deb, M.L. Myers, R. Novick, F.D. Rubens, S.K. Singh, T. Yau; Participating Cardiologists: D. Almond (Victoria Hospital, London, Ontario), C. Buller (University of British Columbia, Vancouver), E.A. Cohen (University of Toronto, Toronto), L. Dragatakis (McGill University, Montreal), L. Higginson (University of Ottawa Heart Institute, Ottawa), L. Schwartz (University of Toronto, Toronto), W. Tymchak (University of Alberta Hospital, Edmonton), R. Watson (University of Toronto, Toronto); Data Committee: M. Afshar, K. Algarni, S. Deb, R. Feder-Elituv, J. Sever, D. Une (all at University of Toronto, Toronto); Statisticians: M. Katik, A. Kiss (all at University of Toronto, Toronto); Angiographic Committee: E.A. Cohen, J. Dubbin, D. Ko, A. Moody, V. Pen, S. Radhakrishnan, L. Schwartz (all at the University of Toronto, Toronto); Clinical End-Points Committee: C. Joyner, F. Moussa, M. Myers (all at the University of Toronto, Toronto); Investigators: Health Sciences Centre, Winnipeg, Manitoba: D. Del Rizzo; Institute de Cardiologie de Montreal, Montreal: M. Carrier, R. Cartier, Y. Leclerc; London Health Sciences Center: University Campus, London, Ontario: D. Boyd, A. Menkis, R. Novick; London Health Sciences Center: Victoria Campus, London, Ontario: M.L. Myers; Montreal General Hospital, Montreal: J.F. Morin, D. Shum-Tim; St. Michael's Hospital, Toronto: D. Bonneau, L. Errett, D. Latter; Sunnybrook Health Sciences Centre, Toronto: L. Abouzhar, G. Bhatnagar, G.T. Christakis, C. Cutrara, S.E. Fremes, B. Goldman; Toronto General Hospital, Toronto: S. Brister, R.J. Cusimano, C. Peniston, A. Ralph-Edwards, H. Scully, R. Weisel, T. Yau; University of Alberta Hospital, Edmonton: E. Gelfand, P. Penkoske; University of Ottawa Heart Institute, Ottawa: F.D. Rubens; Vancouver Hospital and Health Sciences Centre, Vancouver, BC: L. Burr, G. Fradet, D. Thompson; Site Coordinators: R. Feder-Elituv, S. Finlay, R. Fox, S. Fox, S. Germain, L. Harris, N. Hsu, MA. James, C. Jesina, M. Keith, R. Mokbel, L. Montebruno, A. Munoz, C. Nacario, S. Naidoo, R. Sohal, K. Tsang. Received for publication April 14, 2014; revisions received June 10, 2014; accepted for publication June 27, 2014; available ahead of print Aug 7, 2014.

Address for reprints: Stephen E. Fremes, MD, University of Toronto, Schulich Heart Centre, Sunnybrook Health Sciences Centre, 2075 Bayview Ave, Room H405, Toronto, Ontario, Canada M4N 3M5 (E-mail: stephen.fremes@sunnybrook.ca). 0022-5223/\$36.00

Copyright (C) 2014 by The American Association for Thoracic Surgery http://dx.doi.org/10.1016/j.jtcvs.2014.06.057 


$$
\begin{aligned}
& \text { Abbreviations and Acronyms } \\
& \begin{aligned}
\text { CABG } & =\text { coronary artery bypass grafting } \\
\text { CI } & =\text { confidence interval } \\
\text { CTA } & =\text { computed tomography angiography } \\
\text { ECG } & =\text { electrocardiogram } \\
\text { ITA } & =\text { internal thoracic artery } \\
\text { LVEF } & =\text { left ventricular ejection fraction } \\
\text { MACE } & =\text { major adverse cardiac events } \\
\text { MI } & =\text { myocardial infarction } \\
\text { OR } & =\text { odds ratio } \\
\text { PCI } & =\text { percutaneous coronary intervention } \\
\text { RA } & =\text { radial artery } \\
\text { RAPS } & =\text { Radial Artery Patency Study } \\
\text { SV } & =\text { saphenous vein }
\end{aligned}
\end{aligned}
$$

Diabetes mellitus currently affects more than 285 million adults in the world and is projected to increase to 439 million by $2030 .{ }^{1}$ A large portion of deaths in diabetic patients are associated with ischemic heart disease. ${ }^{2}$ Coronary artery bypass grafting $(\mathrm{CABG})$ is considered the standard of care in diabetic patients with advanced multivessel disease. This was confirmed in the international multicenter randomized study (Future Revascularization Evaluation in Patients with Diabetes Mellitus: Optimal Management of Multivessel Disease), ${ }^{3}$ which showed that in diabetic patients with multivessel disease, CABG resulted in a significantly reduced rate of major adverse cardiac events (MACE) (all-cause death, nonfatal myocardial infarction [MI], and nonfatal stroke) compared with percutaneous coronary intervention (PCI) at 5 years (18.7\% CABG vs $26.6 \%$ PCI, $P=.005$ ); these findings were included in a recent systematic review that suggested CABG should be revised to a class I, level A recommendation in diabetic patients with multivessel disease in both the American and the European revascularization guidelines. ${ }^{4}$

An important predictor of long-term success in CABG is graft patency. ${ }^{5}$ This is especially true in diabetic patients because they are prone to diffuse and rapidly progressive atherosclerosis. $^{2}$ Because of the excellent long-term patency rates and resistance to atherosclerosis of internal thoracic artery (ITA) grafts, ${ }^{6,7}$ surgeons have turned to the radial artery (RA) as another potential arterial conduit. A recent meta-analysis showed that RA grafts were superior to saphenous vein (SV) grafts at midterm angiographic follow-up. ${ }^{8}$ The Radial Artery Patency Study (RAPS) is a multicenter randomized trial comparing the patency of the RA with the SV (NCT00187356). The RAPS investigators reported that the proportion of RAs with complete graft occlusion was lower than SVs at 1 year $(8.2 \%$ vs $13.6 \%$, $P=.009)^{9}$ and more than 5 years $(8.9 \%$ vs $18.6 \%$, $P=.002) .{ }^{10}$ At 1 year, the RAs were superior to the SVs in the diabetic cohort with respect to graft patency. ${ }^{11}$
We report the long-term (>5years) impact of diabetic status on RA and SV graft patency. Specifically, the primary objective is to determine whether preoperative diabetic status differentially influences long-term complete occlusion between the RA and study SV grafts. The secondary objective is to determine the potential predictors of long-term complete graft occlusion. The tertiary objective is to determine whether diabetic status influences longterm, event-free survival after CABG.

\section{METHODS}

This is a secondary analysis of the RAPS, which is a longitudinal, multicenter, randomized, controlled clinical trial for which institutional research ethics approval was attained. All participants who were enrolled in the trial provided informed consent.

\section{Population}

Details of the RAPS protocol have been published. ${ }^{12}$ Briefly, the RAPS included patients aged less than 80 years with left ventricular ejection fraction (LVEF) greater than $35 \%$ and triple-vessel coronary disease undergoing nonemergency isolated CABG. Angiographic inclusion criteria were target vessel stenosis of $70 \%$ or greater to decrease the likelihood of competitive flow from the native circulation, vessel diameter of $1.5 \mathrm{~mm}$ or greater, and target vessel deemed to be of acceptable quality. Exclusion criteria were contraindications to the use of the RA (ie, positive Allen's test, abnormal arterial upper limb duplex scan, or a history of vasculitis or Raynaud's syndrome) or the SV (ie, bilateral varicosities or vein stripping). Further exclusion criteria were factors limiting follow-up research angiography, which included creatinine greater than $180 \mu \mathrm{mol} / \mathrm{L}$, severe peripheral vascular disease limiting femoral access, coagulopathy or obligatory use of anticoagulants, known allergy to radiographic contrast, pregnancy, and geographic inaccessibility.

\section{Randomization}

A within-patient randomization design was applied whereby the RA was randomized to the inferior (right coronary artery) or lateral (circumflex artery) region of the heart. The study SV graft would then be placed at the opposing territory (circumflex artery or right coronary artery). This technique allowed patients to receive both study grafts and serve as their own internal control. The ITA was used for the anterior wall (left anterior descending) distribution. The randomization schedule was obtained using a central computer random number sequence generator and was stratified by center in randomly varying blocks of 4-6. Randomization was concealed in a sealed opaque envelope and revealed to the surgeon only after the patient entered the operating room.

\section{Surgical Technique and Perioperative Management}

Both the RA and the SV were harvested using an open technique. The nondominant hand was used to harvest the RA. All operations were performed on-pump using cardiopulmonary bypass. Grafts were performed with a single distal and proximal aortocoronary anastomosis; sequential and composite grafts were not performed. Details of the harvesting technique have been published. ${ }^{13}$ Each participating surgeon partook in a 2-day workshop held in Toronto, Canada, at the beginning of the study to learn the standard RA harvesting technique and could recruit patients after performing the operation in 3 patients.

\section{Postoperative Management}

Patients received $325 \mathrm{mg}$ of aspirin within 6 hours postoperatively and daily thereafter; a lower dose of aspirin was used long-term according to institutional practice. Intravenous nitroglycerin was administered during 
the first 24 hours postoperatively, and vasopressors were avoided. Oral calcium-channel blockade (long-acting nifedipine $30 \mathrm{mg} / \mathrm{d}$ ) was initiated on the first postoperative day and continued for at least 6 months. Other postoperative care was individualized according to the study center's preference. Patients were interviewed by telephone at 1 month, 3 months, 6 months, and yearly thereafter for a maximum of 10 years postoperatively.

Patients had serial electrocardiograms (ECGs) preoperatively and on the first and fifth postoperative days, which were stripped of patient identifiers and read centrally by a core ECG committee, consisting of 3 cardiologists not otherwise associated with the study. The ECGs were read centrally in a blinded fashion and without any details of the perioperative course of the patient. Perioperative cardiac enzymes were measured according to the routine institutional practice, but the results were not reviewed by the ECG committee. A perioperative MI was diagnosed when persistent new pathologic $\mathrm{Q}$ waves were present on the postoperative ECGs. A diagnosis of a perioperative MI required a decision of 2 of the 3 reviewing cardiologists.

\section{Follow-up}

Angiography. Patients were approached to undergo invasive angiography at least 5 years after CABG. All participating sites acquired angiograms digitally, and the image sequences were transferred to compact discs that were sent to the main study center for centralized reading. Patients who declined invasive x-ray angiography were offered the option of computed tomography angiography (CTA). Details of the angiography protocol have been explained elsewhere. ${ }^{10}$ All invasive and CTA scans were read centrally. Each invasive angiogram was independently adjudicated in a blinded fashion by 2 invasive cardiologists, with a third review in the case of disagreement of the primary or secondary outcome. Each CTA scan was reviewed by an imaging cardiologist and a thoracic radiologist.

Clinical. Patients were interviewed by telephone at 1 month, 3 months, 6 months, and yearly thereafter for a maximum of 10 years postoperatively. If the patient had been hospitalized for cardiac reasons between interviews, inpatient records were obtained. Data on death, cause of death, nonfatal MI, and repeat revascularization were obtained at each interview. All clinical events were reviewed centrally in a blinded fashion by a committee consisting of 2 cardiologists and 1 cardiac surgeon.

\section{Statistical Analysis}

Baseline demographics were compared between diabetic and nondiabetic patients. A 2-sample $t$ test and the Wilcoxon rank-sum test were used for parametric and nonparametric continuous variables, respectively. All categoric variables (reported as frequency and percentage) were compared between the diabetic and nondiabetic cohorts using the chi-square test.

The primary objective was to determine the rate of complete graft occlusion at more than 5 years after surgery between the RA and the SV on the basis of preoperative diabetic status. Complete occlusion was defined by invasive angiography as a Thrombolysis in Myocardial Infarction score of 0 or occlusion according to CTA between diabetic and nondiabetic patients. To address the primary objective of determining whether diabetic status had a differential effect on RA and SV graft occlusion, 2 types of univariate analysis were performed. The first analysis compared occlusion rates between the grafts (intergraft comparison of RA vs SV) with respect to diabetic status; given the paired nature of this comparison, the McNemar test was performed as the test of significance.

The second analysis compared occlusion rates within each graft type (intragraft comparison) with respect to diabetic status; the chi-square test was used to test independent proportions.

The secondary objective was to determine potential predictors of complete graft occlusion. Given the paired nature of the study design, general estimation equation modeling was used as the predictor model. The a priori potential variables that were tested in the model were baseline demographics, including diabetic status, age, gender, hyperlipidemia, creatinine ( $10 \mu \mathrm{mol} / \mathrm{L}$ increments), peripheral vascular disease, smoking status (any smoking history vs never smoked), and proximal native disease of target vessels ( $\geq 90 \%$ vs $70 \%-89 \%$ stenosis), along with graft type (RA or SV). The interaction term between diabetes and graft type also was tested. Before modeling, the variables were assessed for multicollinearity (tolerance statistic $<0.4$ ). Because of the relatively small number of graft occlusions, bootstrapping was used to validate the model with 5000 iterations with replacement. The median odds ratio (OR) and its $95 \%$ confidence interval (CI) of each of the prespecified covariates from the bootstrap were compared with the original model. The percentage of times the $P$ value was less than .05 during the 5000 iterations for each covariate also was determined.

The cumulative patency of the RA and SV grafts was compared on the basis of the early ( 1 year) and late angiography ( $>5$ years) after CABG. All patients were right censored at their last angiogram if they did not have an event (ie, complete occlusion). Cumulative patency curves for complete occlusion included any patient who had early or late angiograms. The log-rank test was used to compare differences in the cumulative patency curves between diabetic and nondiabetic patients for each conduit.

The tertiary objective was to determine whether there was a difference in the proportion of MACE, defined as cardiac death, late MI, or repeat reintervention, as well as the individual components of MACE in addition to all-cause mortality between diabetic and nondiabetic patients. A chi-square test was used to compare these clinical events with respect to diabetic status. The log-rank test was used to compare differences in event-free survival function (ie, free from MACE) between diabetic and nondiabetic patients. SAS version 9.4 (SAS Institute Inc, Cary, NC) was used for all analysis.

\section{RESULTS \\ Patient Population}

In the RAPS long-term study, 529 patients across 11 centers underwent late clinical follow-up at a mean of $7.3 \pm 2.9$ years, of whom $148(28.0 \%)$ had diabetes, $114(77.0 \%)$ had noninsulin-dependent diabetes, and $34(23.0 \%)$ had insulin-dependent diabetes at the time of CABG. Nine centers $(\mathrm{n}=510)$ participated in late angiographic follow-up; after excluding early deaths $(\mathrm{n}=18)$, protocol violations $(\mathrm{n}=16)$, both study graft occlusions at early angiography $(\mathrm{n}=3)$, new medical exclusions $(\mathrm{n}=64)$, excessive distance $(\mathrm{n}=8)$, and loss to follow-up $(\mathrm{n}=43), 358$ patients were eligible for late angiographic analysis. After excluding late deaths $(\mathrm{n}=6)$ and patient refusal $(\mathrm{n}=83)$, 269 patients $(75.1 \%$ of eligible patients, 83 [30.9\%] diabetic) underwent late angiography (234 underwent invasive $\mathrm{x}$-ray angiography, 35 underwent $\mathrm{CTA}$ ) at a mean angiographic follow-up of $7.7 \pm 1.5$ years after CABG. Of these, 25 of 269 were clinically directed and the remainder were mandated by the research protocol. As previously published, the nonangiographic cohort had a higher incidence of peripheral vascular disease compared with the angiographic cohort at baseline. ${ }^{10}$ Baseline demographics were generally similar between diabetic and nondiabetic patients for both the nested angiographic and larger late clinical follow-up cohorts (Table 1). The proportions of female gender and hyperlipidemia were increased in the diabetic patients. 
TABLE 1. Baseline characteristics of diabetic and nondiabetic patients*

\begin{tabular}{|c|c|c|c|c|c|c|}
\hline \multirow[b]{2}{*}{ Characteristics } & \multicolumn{2}{|c|}{ Late clinical follow-up cohort $(\mathrm{N}=529)$} & \multirow[b]{2}{*}{$\begin{array}{c}P \\
\text { value }\end{array}$} & \multicolumn{2}{|c|}{ Late angiographic cohort $(N=269)$} & \multirow[b]{2}{*}{$\begin{array}{c}P \\
\text { valu }\end{array}$} \\
\hline & $\begin{array}{l}\text { Diabetic patients } \\
\quad(N=148)\end{array}$ & $\begin{array}{c}\text { Nondiabetic patients } \\
(\mathbf{N}=\mathbf{3 8 1})\end{array}$ & & $\begin{array}{l}\text { Diabetic patients } \\
(\mathbf{N}=\mathbf{8 3})\end{array}$ & $\begin{array}{c}\text { Nondiabetic patients } \\
\quad(\mathbf{N}=\mathbf{1 8 6})\end{array}$ & \\
\hline Age, y $($ mean $\pm S D)$ & $59.9 \pm 7.7$ & $60.8 \pm 8.7$ & .17 & $59.4 \pm 7.6$ & $60.1 \pm 8.3$ & .42 \\
\hline Age > 70 y, no. $(\%)$ & $17(11.5)$ & $63(16.5)$ & .15 & $7(8.4)$ & $25(13.4)$ & .24 \\
\hline Elective surgery, no. $(\%)$ & $93(62.8)$ & $251(65.9)$ & .51 & $54(65.1)$ & $122(65.6)$ & .93 \\
\hline Previous MI, no. $(\%)$ & $71(48.0)$ & $174(45.7)$ & .63 & $36(43.4)$ & $88(47.3)$ & .55 \\
\hline Female sex, no. $(\%)$ & $27(18.2)$ & 44 (11.6) & .04 & $18(21.7)$ & $23(12.4)$ & .05 \\
\hline CCS class of angina, no. $(\%)$ & & & .63 & & & .79 \\
\hline 1 & $2(1.4)$ & $8(2.1)$ & & $2(2.4)$ & $2(1.1)$ & \\
\hline 2 & $35(23.7)$ & 94 (24.7) & & $17(20.5)$ & $42(22.6)$ & \\
\hline 3 & $66(44.6)$ & $183(48.0)$ & & $41(49.4)$ & $96(51.6)$ & \\
\hline 4 & $45(30.4)$ & $96(25.2)$ & & $23(27.7)$ & $46(24.7)$ & \\
\hline Congestive heart failure, no. (\%) & $9(6.1)$ & $7(1.8)$ & .01 & $2(2.4)$ & $3(1.6)$ & .65 \\
\hline Hypertension, no. (\%) & $82(55.4)$ & $178(46.7)$ & .07 & $39(47.0)$ & $82(44.1)$ & .66 \\
\hline Hypercholesterolemia, no. (\%) & $109(74.2)$ & $240(63.0)$ & .01 & $64(78.1)$ & $125(67.2)$ & .07 \\
\hline Smoking history, no. (\%) & $111(75.0)$ & $267(70.1)$ & .26 & $61(73.5)$ & $131(70.4)$ & .61 \\
\hline Creatinine $\mu \mathrm{mol} / \mathrm{L}(\mathrm{mean} \pm \mathrm{SD})$ & $93.0 \pm 18.6$ & $93.5 \pm 19.4$ & .91 & $91.1 \pm 16.0$ & $93.1 \pm 18.0$ & .92 \\
\hline Peripheral vascular disease, no. $(\%)$ & $13(8.8)$ & $33(8.7)$ & .96 & $5(6.0)$ & $11(5.9)$ & 1.00 \\
\hline LV grade, no. $(\%) \dagger$ & & & .26 & & & .61 \\
\hline 1 & $60(40.5)$ & $188(49.3)$ & & $37(44.6)$ & $96(51.6)$ & \\
\hline 2 & $86(58.1)$ & $186(48.8)$ & & $45(54.2)$ & $86(46.2)$ & \\
\hline 3 & $2(1.4)$ & $6(1.6)$ & & $1(1.2)$ & $3(1.6)$ & \\
\hline 4 & 0 & $1(0.3)$ & & $0(0)$ & $1(0.5)$ & \\
\hline \multicolumn{7}{|l|}{ Target vessel stenosis, no. (\%) } \\
\hline Right coronary artery & & & .61 & & & .58 \\
\hline $70 \%-89 \%$ stenosis & 44 (29.7) & $122(32.0)$ & & $24(28.9)$ & $60(32.3)$ & \\
\hline$\geq 90 \%$ stenosis & $104(70.3)$ & $259(68.0)$ & & $59(71.1)$ & $126(67.7)$ & \\
\hline Circumflex artery & & & .13 & & & .34 \\
\hline $70 \%-89 \%$ stenosis & $75(50.7)$ & $165(43.3)$ & & $39(47.0)$ & $76(40.9)$ & \\
\hline$\geq 90 \%$ stenosis & $73(49.3)$ & $216(56.7)$ & & $44(53.0)$ & $110(59.1)$ & \\
\hline RA target vessel & & & .13 & & & .66 \\
\hline $70 \%-89 \%$ stenosis & $67(45.3)$ & $145(38.1)$ & & $34(41.0)$ & $71(38.2)$ & \\
\hline$\geq 90 \%$ stenosis & $81(54.7)$ & $236(61.9)$ & & $49(59.0)$ & $115(61.8)$ & \\
\hline SV target vessel & & & .65 & & & .99 \\
\hline $70 \%-89 \%$ stenosis & $52(35.1)$ & $142(37.3)$ & & $29(35.0)$ & $65(35.0)$ & \\
\hline$\geq 90 \%$ stenosis & $96(64.9)$ & $239(62.7)$ & & $54(65.1)$ & $121(65.1)$ & \\
\hline
\end{tabular}

$C C S$, Canadian Cardiovascular Society; $L V$, left ventricular; $M I$, myocardial infarction; $R A$, radial artery; $S D$, standard deviation; $S V$, saphenous vein. *Plus-minus values are means \pm standard deviation. $\nmid$ According to this scale, a grade of 1 indicates an estimated global LVEF of $\geq 50 \%$, a grade of 2 is LVEF of $35 \%$ to $49 \%$, a grade of 3 is LVEF of $20 \%$ to $34 \%$, and a grade of 4 is LVEF $<20 \%$.

\section{Angiographic End Points}

The proportion of completely occluded study grafts at angiography at more than 5 years after CABG (primary end point) was significantly lower in RA grafts (4/83; $4.8 \%)$ compared with SV grafts $(21 / 83 ; 25.3 \%)$ $(P=.0004)$ in diabetic patients (Table 2). In nondiabetic patients, the proportion of completely occluded study grafts was similar (20/186 [10.8\%] RAs, 29/186 [15.6\%] SVs, $P=.19$ ). Within the graft subtypes, the proportion of completely occluded RA grafts was similar irrespective of diabetic status (4/83 [4.8\%] diabetic vs 20/186 [10.8\%] nondiabetic, $P=.11$ ); however, there was a trend toward a higher proportion of SV graft occlusions in the diabetic patients (21/83 [25.3\%] diabetic vs 29/186 [15.6\%] nondiabetic, $P=.06$ ) (Table 3 ). There were no significant differences in RA $(P=1.0)$ and $\mathrm{SV}(P=.75)$ graft occlusions between insulin-dependent $(\mathrm{n}=16)$ and

TABLE 2. Comparison of complete graft occlusion between radial artery and saphenous vein graft by diabetic status

\begin{tabular}{lccc}
\hline & $\begin{array}{c}\text { RA complete } \\
\text { occlusion } \\
\mathbf{n}(\%)\end{array}$ & $\begin{array}{c}\text { SVG complete } \\
\text { occlusion } \\
\mathbf{n}(\%)\end{array}$ & $\begin{array}{c}\boldsymbol{P} \\
\text { value }\end{array}$ \\
\hline Diabetic patients $(\mathrm{N}=83)$ & $4(4.8)$ & $21(25.3)$ & .0004 \\
Nondiabetic patients $(\mathrm{N}=186)$ & $20(10.8)$ & $29(15.6)$ & .19 \\
\hline
\end{tabular}

$P$ values are based on a McNemar test and represent comparison of RA occlusion versus SVG occlusion for the respective diabetic status. $R A$, Radial artery; $S V G$, saphenous vein graft. 
TABLE 3. Comparison of complete graft occlusion of the same conduit between diabetic and nondiabetic patients

\begin{tabular}{lccc}
\hline & $\begin{array}{c}\text { Diabetic } \\
\text { patients } \\
(\mathbf{N}=\mathbf{8 3})\end{array}$ & $\begin{array}{c}\text { Nondiabetic } \\
\text { patients } \\
(\mathbf{N}=\mathbf{1 8 6})\end{array}$ & $\begin{array}{c}\boldsymbol{P} \\
\text { value }\end{array}$ \\
\hline RA complete occlusion n $(\%)$ & $4(4.8)$ & $20(10.8)$ & .11 \\
SV complete occlusion n $(\%)$ & $21(25.3)$ & $29(15.6)$ & .06 \\
RA or SV graft complete occlusion & $24(28.9)$ & $48(25.8)$ & .59 \\
$\quad$ n $(\%)$ & & & \\
\hline
\end{tabular}

$\mathrm{n}(\%)$

$P$ values are based on chi-squares and represent the comparison of diabetic versus nondiabetic patients for the respective conduit (RA or $\mathrm{SV}$ ) occlusion. $R A$, Radial artery; $S V$, saphenous vein.

noninsulin-dependent diabetic patients $(n=67)$. The corresponding occlusion rate of the ITA graft to the left anterior descending territory was $7.8 \%$ in diabetic patients versus $5.1 \%$ in nondiabetic patients $(P=.41)$. RA versus SV graft occlusion was proportionally similar between patients who underwent clinical and protocol-directed angiograms.

General estimation equation modeling was used to determine the predictors of late complete graft occlusion at the graft level (Table 4). There were no interactions between graft type and territory $(P=.54)$. The use of the $\mathrm{RA}$, compared with the SV, was found to be protective against long-term complete graft occlusion (OR, 0.43; $95 \%$ CI, 0.25-0.75; $P=.003$ ). In addition, having greater target native vessel stenosis at the time of surgery ( $\geq 90 \%$ stenosis compared with less stenotic vessels of $70 \%-89 \%$ ) was protective against complete occlusion (OR, 0.59; 95\% CI, 0.35-0.97; $P=.04$ ). Being female (OR, 2.23; 95\% CI, 1.14-4.38; $P=.02$ ) and having a smoking history (OR, 1.49; 95\% CI, 1.01-2.21; $P=.047$ ) were found to be positive predictors of complete graft occlusion along with an elevated creatinine level (OR, $1.17 ; 95 \%$ CI, $1.02-1.35 ; P=.03$, per $10 \mu \mathrm{mol} / \mathrm{L}$ increase). The overall protective effect of the RA graft was influenced by diabetic status (diabetes by graft type interaction $P=.02$ ). To determine model fit, 5000 iterations were performed of the original model. The median OR and its

TABLE 4. Multivariable predictors of complete graft occlusion

\begin{tabular}{lccc}
\hline \multicolumn{1}{c}{ Variable } & OR & $\mathbf{9 5} \%$ CI & $\boldsymbol{P}$ value \\
\hline Female & 2.23 & $1.14-4.38$ & .02 \\
RA graft & 0.43 & $0.25-0.75$ & .003 \\
History of smoking & 1.49 & $1.01-2.21$ & .047 \\
Proximal native vessel disease & 0.59 & $0.35-0.97$ & .04 \\
$\quad(\geq 90 \%$ vs $70 \%-89 \%$ stenosis $)$ & & & \\
Creatinine (per 10 $\mu \mathrm{mol} / \mathrm{L})$ & 1.17 & $1.02-1.35$ & .03 \\
Diabetes & 1.10 & $0.65-1.86$ & .72 \\
Diabetes $\times$ graft type interaction & & & .02 \\
\hline
\end{tabular}

Complete graft occlusion (RA or SV) is defined as Thrombolysis in Myocardial Infarction flow of 0 or nonpatent as assessed by CTA. An OR less than 1 is protective against complete graft occlusion. $C I$, Confidence interval; $O R$, odds ratio; $R A$, radial artery.

\section{Freedom From Radial Artery Graft Occlusion}

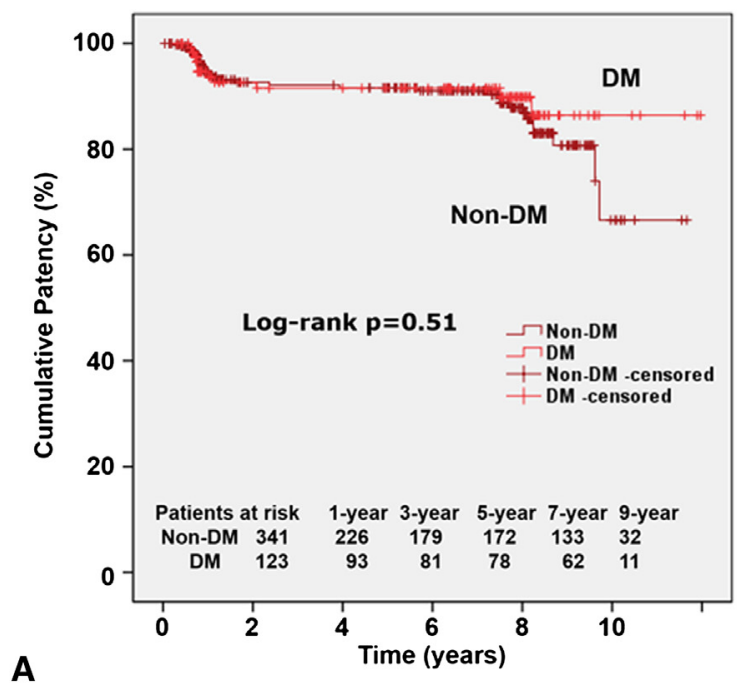

\section{Freedom From Saphenous Vein Graft Occlusion}

\section{B}

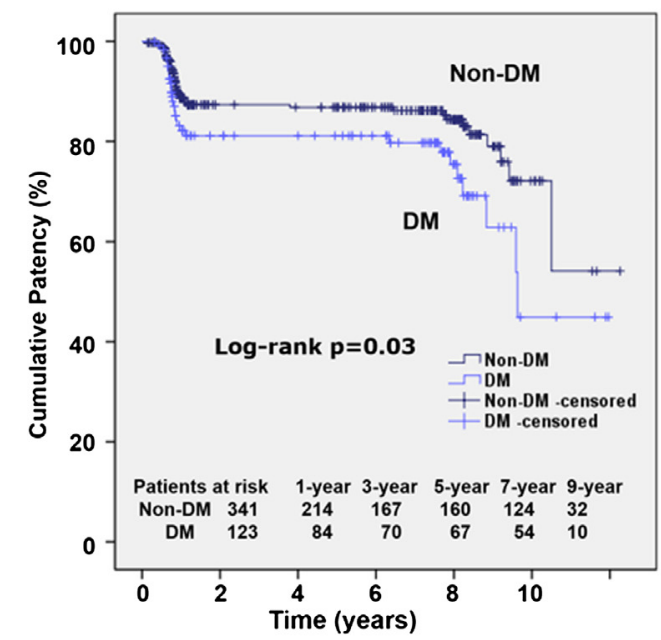

FIGURE 1. A, Freedom from complete occlusion of the RA graft stratified by diabetic status. The $\log$-rank $P$ value is testing for statistical significance of the RA graft patency curve between diabetic and nondiabetic patients. B, Freedom from complete occlusion of the SV stratified by diabetic status. The $\log$-rank $P$ value is testing for statistical significance of the SV graft patency curve between diabetic and nondiabetic patients. $D M$, Diabetes mellitus.

95\% CI were similar to the original model for all of the prespecified covariates. With respect to the covariates that were significant predictors in the original model (female gender, use of an RA graft, any smoking history, creatinine, and severity of proximal native disease), all with the exception of smoking history were significant more than $50 \%$ of times during the 5000 iteration; smoking history was significant $47.3 \%$ of times. The remaining covariates were significant less than $11 \%$ in the 5000 iterations.

Cumulative patency curves were created on the basis of 464 patients undergoing early or late angiography with 
TABLE 5. Clinical end points between diabetic and nondiabetic patients

\begin{tabular}{lccc}
\hline & $\begin{array}{c}\text { Diabetic } \\
\text { patients } \\
(\mathbf{N}=\mathbf{1 4 8})\end{array}$ & $\begin{array}{c}\text { Nondiabetic } \\
\text { patients } \\
(\mathbf{N}=\mathbf{3 8 1})\end{array}$ & $\begin{array}{c}\boldsymbol{P} \\
\text { value }\end{array}$ \\
\hline MACE n (\%) & $23(15.5)$ & $35(9.2)$ & .04 \\
All-cause death n (\%) & $19(12.8)$ & $42(11.0)$ & .56 \\
Cardiac death n (\%) & $10(6.8)$ & $16(4.2)$ & .22 \\
Late nonfatal MI n (\%) & $5(3.4)$ & $5(1.3)$ & .11 \\
Reintervention (PCI or CABG) & $11(7.4)$ & $16(4.2)$ & .13 \\
\hline
\end{tabular}

$P$ value compares the proportions of clinical events between diabetic and nondiabetic patients. MACE defined by cardiac death, late nonfatal MI, reintervention by stent, or redo CABG. $C A B G$, Coronary artery bypass grafting; $M A C E$, major adverse cardiac events; $M I$, myocardial infarction; $P C I$, percutaneous coronary intervention.

complete occlusion being the failure event. Cumulative patency was similar for the RA irrespective of diabetic status (at 7.5 years, diabetic patients: $91.5 \% \pm 2.7 \%$ vs nondiabetic patients: $90.3 \% \pm 2.0 \%$, log-rank $P=.51$, Figure 1, A); however, for SV grafts, cumulative patency curves were statistically different (at 7.5 years, diabetic patients: $79.7 \% \pm 3.9 \%$ vs nondiabetic patients: $86.2 \% \pm 2.1 \%, \log$-rank $P=.03$, Figure $1, B)$. There were 236 patients who underwent serial early and late angiograms. Of the $227(96.2 \%)$ nonoccluded RAs at early angiography, $12(5.3 \%)$ became occluded by the second angiogram; for SVs, of the $204(86.4 \%)$ that were nonoccluded, $11(5.4 \%)$ became occluded.

\section{Clinical End Points}

Of the 529 patients who underwent late clinical followup, the proportion of MACE defined as cardiac death, nonfatal late MI, or coronary reintervention (percutaneous intervention or repeat $\mathrm{CABG}$ ) was significantly higher in diabetic patients (MACE: 23/148 [15.5\%] diabetic, $35 / 381[9.2 \%]$ nondiabetic, $P=.04)$. Each of the individual components along with all-cause mortality trended to be higher in the diabetic group: all-cause death (19/148 [12.8\%] diabetic vs 42/381 [11.0\%] nondiabetic, $P=.56)$, cardiac death $(10 / 148[6.8 \%]$ diabetic vs $16 /$ $381[4.2 \%$ ] nondiabetic, $P=.22)$, late MI (5/148 [3.4\%] diabetic vs $5 / 381[1.3 \%]$ nondiabetic, $P=.11$ ), and reintervention (11/148 [7.4\%] diabetic, 16/381 [4.2\%] nondiabetic, $P=.13$ ) (Table 5). Event-free survival from MACE also trended to be lower in diabetic patients (10 years: $72.8 \% \pm 6.1 \%$ diabetic vs $83.4 \% \pm 3.1 \%$ nondiabetic, $P=.05$ ) (Figure 2).

\section{DISCUSSION}

It is well known that diabetic patients have a higher propensity of rapidly progressive atherosclerosis, macrovascular disease, and higher mortality compared with nondiabetic patients. ${ }^{2}$ Consequently, issues of myocardial revascularization in these patients have received much

\section{Freedom From Major Adverse Cardiac Events}

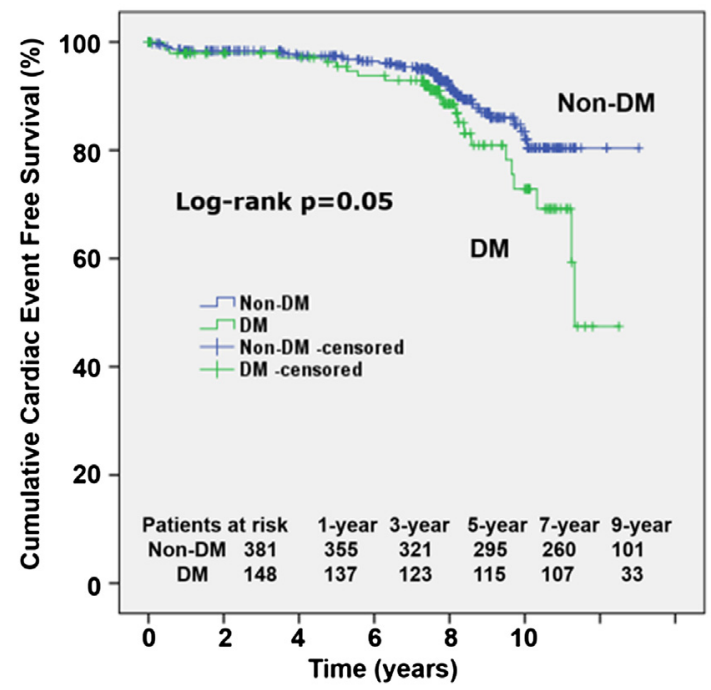

FIGURE 2. MACE-free survival stratified by diabetic status. The log-rank $P$ value is testing for statistical significance of the MACE curves between diabetic and nondiabetic patients. MACE is defined as cardiac death, late MI, or repeat reintervention of PCI or CABG. DM, Diabetes mellitus.

attention favoring CABG over PCI, especially in diabetic patients with advanced coronary disease., ${ }^{3,4,14,15}$ The long-term success of CABG is dependent on graft patency and appropriate conduit choice. The RAPS is the first multicenter within-patient randomized trial comparing RA and SV grafts in patients undergoing late angiography at more than 5 years after CABG.

The main finding of this substudy was that the SVs compared with RAs had a higher proportion of complete graft occlusions 5 years or more after CABG in diabetic patients. Compared with nondiabetic patients, SV occlusions were higher in diabetic patients. Furthermore, although the use of an RA along with a higher grade of target vessel stenosis was protective against late complete occlusion, female gender, smoking history, and elevated creatinine were predictors of complete occlusion. There was also an interaction between diabetes and the type of graft used. Finally, although univariate analysis showed that RAs had a nonsignificantly higher occlusion rate in patients without diabetes (Table 2), the almost identical RA patency curves with respect to diabetic status were reassuring (Figure 1); the counterintuitive univariate finding may have been due to the low number of events. The graft occlusion findings in this study are consistent with our earlier publication of 1-year angiography results, which also showed that SV grafts had a higher occlusion rate in diabetic patients than in nondiabetic patients $(19 \%$ vs $12 \%, P=.04) .{ }^{11}$ At both early and late angiography, RA patency was statistically similar with respect to diabetic status, and the use of the RA was protective against complete graft occlusion. Of the randomized trials comparing 
RAs with SVs to date, the Veterans Affairs Cooperatives Study Program was the only other study that reported a potential influence of diabetes on RA and SV graft patency ${ }^{16}$; of note, they found that RAs had a lower patency compared with SVs in diabetic patients and that the opposite was true for nondiabetic patients. This is in contrast to our findings and may have been due to their shorter follow-up period of 1 year. The lack of female patients, the possible differences with regard to target vessel stenosis, and the surgeons' discretion of target for the study conduit (compared with the randomized targets in RAPS) also may have led to differential findings in the Veterans Affairs Cooperatives Study Program. A recent study by Schwann and colleagues, ${ }^{17}$ using propensity-matched analysis, showed that the ITA and RA groups conferred a significant late-survival advantage (16-year follow-up) in diabetic patients compared with the ITA and SV groups (hazard ratio, $0.78 ; 95 \% \mathrm{CI}, 0.65-0.95 ; P=.012)$. Another propensity-matched study by Tranbaugh and associates ${ }^{18}$ showed that diabetic patients who underwent CABG had a relative $57 \%$ increased 10 -year mortality with SV grafts compared with RA grafts.

These findings are suggestive of SV grafts doing poorly in diabetic patients compared with RA grafts. The phenomenon of SV grafts performing inferiorly to RA grafts was observed in the Bypass Angioplasty Revascularization Investigation, which showed that CABG involving the use of the ITA had a substantial survival benefit in diabetic patients compared with CABG involving only SV grafts. ${ }^{19}$ Another recently published study using propensity scores showed that bilateral compared with single ITA use in diabetes was associated with a longer late survival (13.1 vs 9.8 years, $P=.001) .^{20}$

Finally, the proportion of MACE was higher in diabetic patients compared with nondiabetic patients. Although the individual components of MACE were all nonsignificantly higher in diabetic patients, the higher MACE in diabetic patients may have been driven by higher reintervention rates, which had the highest absolute risk difference $(3.2 \%)$. The difference in clinical event rates between those with and without diabetes is likely underestimated in our study because of the within-patient randomization design in which each patient received both the RA and the SV, biasing our findings toward the null.

\section{Study Limitations}

The RAPS generally recruited low-risk patients. Patients who underwent late angiography had a lower incidence of hypertension and peripheral vascular disease compared with the cohort that did not undergo angiography. The use of within-patient randomization allowed patients to serve as their own controls, decreasing confounding bias; however, this design did not allow for independent comparisons of clinical outcomes based on graft type. Furthermore, during follow-ups, there were no assessments of hemoglobin A1c status; therefore, the severity or control of diabetes in these patients was not clear. In addition, although $75 \%$ of eligible patients underwent late angiography, the absolute number and the consequent event rates were small; therefore, the findings from this study should be considered hypothesis generating and further corroborated in larger studies. Finally and perhaps related to the small number of events is the unexpected finding of RA and SV graft occlusions being qualitatively different (ie, the proportion of RA occlusion was lower in diabetic patients than in nondiabetic patients, whereas for SVs, it was higher in diabetic patients than in nondiabetic patients).

\section{CONCLUSIONS}

RAs are associated with a lower proportion of late graft occlusion compared with SVs in diabetic patients. Furthermore, although severe target vessel stenosis $(\geq 90 \%)$ is protective, female gender, smoking history, and elevated creatinine are predictors of late graft occlusion. Finally, nondiabetic patients had a lower proportion of late MACE compared with diabetic patients. Our observational data from the prospectively randomized RAPS support the use of the RA as a second conduit compared with the SV in diabetic patients.

\section{References}

1. Shaw JE, Sicree RA, Zimmet PZ. Global estimates of the prevalence of diabetes for 2010 and 2030. Diabetes Res Clin Pract. 2010;87:4-14.

2. Aronson D, Edelman ER. Revascularization for coronary artery disease in diabetes mellitus: angioplasty, stents and coronary artery bypass grafting. Rev Endocr Metab Disord. 2010;11:75-86.

3. Farkouh ME, Domanski M, Sleeper LA, Siami FS, Dangas G, Mack M, et al. Strategies for multivessel revascularization in patients with diabetes. $N$ Engl J Med. 2012;367:2375-84.

4. Deb S, Wijeysundera HC, Ko DT, Tsubota H, Hill S, Fremes SE. Coronary artery bypass graft surgery vs percutaneous interventions in coronary revascularization: a systematic review. JAMA. 2013;310:2086-95.

5. Goldman S, Copeland J, Moritz T, Henderson W, Zadina K, Ovitt T, et al. Long-term graft patency (3 years) after coronary artery surgery. Effects of aspirin: results of a VA Cooperative study. Circulation. 1994;89:1138-43.

6. Otsuka F, Yahagi K, Sakakura K, Virmani R. Why is the mammary artery so special and what protects it from atherosclerosis? Ann Cardiothorac Surg. 2013;2:519-26.

7. Goldman S, Zadina K, Moritz T, Ovitt T, Sethi G, Copeland JG, et al. Long-term patency of saphenous vein and left internal mammary artery grafts after coronary artery bypass surgery: results from a Department of Veterans Affairs Cooperative Study. J Am Coll Cardiol. 2004;44:2149-56.

8. Cao C, Manganas C, Horton M, Bannon P, Munkholm-Larsen S, Ang SC, et al. Angiographic outcomes of radial artery versus saphenous vein in coronary artery bypass graft surgery: a meta-analysis of randomized controlled trials. J Thorac Cardiovasc Surg. 2013;146:255-61.

9. Desai ND, Cohen EA, Naylor CD, Fremes SE. A randomized comparison of radial-artery and saphenous-vein coronary bypass grafts. N Engl J Med. 2004; 351:2302-9.

10. Deb S, Cohen EA, Singh SK, Une D, Laupacis A, Fremes SE. Radial artery and saphenous vein patency more than 5 years after coronary artery bypass surgery: results from RAPS (Radial Artery Patency Study). J Am Coll Cardiol. 2012;60: 28-35.

11. Singh SK, Desai ND, Petroff SD, Deb S, Cohen EA, Radhakrishnan S, et al. The impact of diabetic status on coronary artery bypass graft patency: insights from the radial artery patency study. Circulation. 2008;118(14 Suppl):S222-5. 
12. Fremes SE. Multicenter radial artery patency study (RAPS). Study design. Control Clin Trials. 2000;21:397-413.

13. Fremes SE, Christakis GT, Del Rizzo DF, Musiani A, Mallidi H, Goldman BS. The technique of radial artery bypass grafting and early clinical results. $J$ Card Surg. 1995;10:537-44.

14. Kappetein AP, Head SJ, Morice MC, Banning AP, Serruys PW, Mohr FW, et al. Treatment of complex coronary artery disease in patients with diabetes: 5-year results comparing outcomes of bypass surgery and percutaneous coronary intervention in the SYNTAX trial. Eur J Cardiothorac Surg. 2013;43:1006-13.

15. Verma S, Farkouh ME, Yanagawa B, Fitchett DH, Ahsan MR, Ruel M, et al. Comparison of coronary artery bypass surgery and percutaneous coronary intervention in patients with diabetes: a meta-analysis of randomised controlled trials. Lancet Diabetes Endocrinol. 2013;1:317-28.

16. Goldman S, Sethi GK, Holman W, Thai H, McFalls E, Ward HB, et al. Radial artery grafts vs saphenous vein grafts in coronary artery bypass surgery: a randomized trial. JAMA. 2011;305:167-74.

17. Schwann TA, Al-Shaar L, Engoren M, Habib RH. Late effects of radial artery vs saphenous vein grafting for multivessel coronary bypass surgery in diabetics: a propensity-matched analysis. Eur J Cardiothorac Surg. 2013;44:701-10.

18. Tranbaugh RF, Dimitrova KR, Friedmann P, Geller CM, Harris LJ, Stelzer P, et al. Radial artery conduits improve long-term survival after coronary artery bypass grafting. Ann Thorac Surg. 2010;90:1165-72.

19. BARI INVESTIGATORS. Seven-year outcome in the Bypass Angioplasty Revascularization Investigation (BARI) by treatment and diabetic status. J Am Coll Cardiol. 2000;35:1122-9.

20. Dorman MJ, Kurlansky PA, Traad EA, Galbut DL, Zucker M, Ebra G. Bilateral internal mammary artery grafting enhances survival in diabetic patients: a 30-year follow-up of propensity score-matched cohorts. Circulation. 2012;126: 2935-42.

\section{Discussion}

Dr Jack Boyd (Indianapolis, Ind). I have 3 questions for you, and it's more extrapolating from your study. The first one is, what do you contribute the higher rate of late RA occlusions to in nondiabetic patients? Although it wasn't statistically significant, it was more than double the percentage.

Dr Deb. The univariate analysis did show that. From a physiology standpoint, it didn't make sense. However, when you see the patency curves of the RA grafts between diabetic and nondiabetic patients, they're almost similar. A large portion of that difference is probably because of the low number of events. So I don't think there is a scientific reasoning for this finding. I think it has to do with the numbers. But seeing the patency curves, we're more comforted by the fact that they're fairly similar.

Dr Boyd. My second question even goes a little bit further off topic from your study, but I'm interested in what your left ITA patency rates were on the angiographic data. Did you have that information available to you because I think that would be significant in the late MACE and the other graft patencies.

Dr Deb. We didn't present it here, but left ITA patency was greater than $94 \%$ overall.

Dr Boyd. Was there any difference between the diabetic and nondiabetic groups?

Dr Deb. We did not assess that.

Dr Boyd. How has this influenced the practice of your group? Do you not use RAs in nondiabetic patients because they have the same patency rate as an SV graft? How does that influence the practice at your institution?

Dr Deb. This is the first study from a clinical trial that actually looked at such long-term outcomes between arterial and venous grafts, and this is the first study that showed from a clinical trial standpoint that RAs were protective in diabetic patients. Two large observational studies also showed, using a propensity score match, that RAs did better in diabetic patients.

With respect to our center, we use RAs a lot. Hopefully, the 10-year results of the Radial Artery Patency and Clinical Outcomes trial and other large studies will further corroborate our findings and encourage others to use RA grafting in diabetic patients. In this whole conference, there has been a push toward RA grafting, especially evident in the last few sessions.

Dr Boyd. Yes, I thought you could have given your presentation upstairs at the plenary session earlier this afternoon.

Dr Deb. Bilateral ITAs and RAs were the highlights there, and I hope this encourages more RA grafting.

\section{EDITORIAL COMMENTARY}

\section{Arterial grafting and the challenge of the patient with diabetes}

\section{Paul A. Kurlansky, MD}

Diabetes currently affects 29.1 million Americans, approximately $9.3 \%$ of the population. The prevalence has more than doubled in the past decade, and current estimates predict an incidence between 1 in 5 and 1 in 3 by the year 2050.

\footnotetext{
From Columbia University, New York, NY

Disclosures: Author has nothing to disclose with regard to commercial support. Received for publication Aug 17, 2014; accepted for publication Aug 18, 2014 Address for reprints: Paul A. Kurlansky, MD, Columbia University, Black Building Q2 210, CUMC, 650 W 168th St, New York, NY 10032 (E-mail: pk2245@ cumc.columbia.edu).
}

Adults with diabetes are 2 to 4 times more likely to have cardiovascular disease than are those without it, and at least $65 \%$ will die of it. In an era when preventive and therapeutic measures have resulted in a progressive and dramatic decline in cardiovascular mortality, the scourge of diabetes,

J Thorac Cardiovasc Surg 2014;148:1253-6 0022-5223/ $\$ 36.00$

Copyright (C) 2014 by The American Association for Thoracic Surgery http://dx.doi.org/10.1016/j.jtcvs.2014.08.026 